\title{
ECOLOGICAL ECONOMICS: A BETTER FRAMEWORK FOR SUSTAINABLE DEVELOPMENT
}

\author{
U.A.D.P. Gunawardena \\ Department of Forestry and Environmental Science, \\ University of Sri Jayewardenepura
}

Sustainable development has been the focus and the target of many resource management related issues. However, proper definitions and frameworks of action have seemed to be greatly unexplored. This paper aims at providing a framework for sustainable development based on concepts of ecological economics. The main focus will be on the issues of intra and inter generational equity on natural resource use and maintaining non-declining levels of critical natural capital.

The conventional economic view is generally optimistic about the ability of the economic system to overcome natural resource depletion with the help of the technological progress. However, conventional approaches in resource economics limit themselves to only optimal rate of exploitation of a natural resource and determination of optimal pollution discharges. Although such approaches are sensitive to scale issues at the micro level, it is insensitive to the macro level scale of the whole econcmy relative to the ecosystem. Although the market provides space for substituting abundant resources for scarce ones, it is not able to overcome entropy constraints. Such issues are not reflected in Pareto optimality since optimal allocation is independent of whether or not the scale of physical throughput is ecologically sustainable

Therefore is important to recognize the existence of a new constraint on the physical scale of the economy relative to the ecosystem. This constraint has to be set according to the criteria of sustainability and under such constraint, the market will be able to achicve prices which reflect the social value of sustainability.

Unique natural environments and other critical natural capital need special considerations in economic analysis since technology can do little to replicate their ecological, physical and geographical characteristics. In order to determine the social cost and benefits of a decision to develop a previously undeveloped area, it is necessary to know both the preferences of present and future generations who may be affected by that decision. The existing valuation frameworks and discounting in cost benefit analysis have inherent biases against future generations. Recognition of such facts and identifying the means of minimizing such biases are essential in achieving sustainable development.

Ecological economic framework is essentially an extension of environment and resource economics in to the explicit analysis of biophysical constraints and equity among generations.

Proceedings of the Eighth Annual Forestry and Environment Symposium 2002 of the Department of Forestry and Environmental Science. University of Sri Jayewardenepura, Sri Lanka 